\title{
Portal: Aplicativo de ensino voltado aos conteúdos base da Língua Portuguesa do Ensino Fundamental
}

\author{
Djalma A. L. Rodrigues ${ }^{1}$, Melina N. Gomes ${ }^{1}$, Leo M. Silva ${ }^{1}$, José D. P. T. Júnior ${ }^{1}$, \\ Antonio P. N. do Vale ${ }^{2}$ \\ ${ }^{1}$ Instituto Federal de Educação, Ciência e Tecnologia do Rio Grande do Norte (IFRN) \\ Campus Ceará-Mirim - 59570-000 - Ceará-Mirim - RN - Brasil \\ ${ }^{2}$ Instituto Federal de Educação, Ciência e Tecnologia do Paraná (IFPR) \\ Campus Irati - 84500-000 - Irati - PR - Brasil \\ \{antony.lemos, melina.nascimento\} @academico.ifrn.edu.br, \{leo.silva, durv \\ al.pacheco\} difrn.edu.br, peterson. nogueira@ifpr.edu.br
}

\begin{abstract}
This work proposes the creation of a mobile application that aims to teach basic contents of Elementary School in the Portuguese Language course for students entering High School, considering that possible gaps left by previous education - especially the public - may have a negative influence during the process of formation of the individual. In this sense, the Portal is expected to be a support tool for the student, as well as a pedagogical resource to be used by the teacher.
\end{abstract}

Resumo. Este trabalho propõe a criação de um aplicativo móvel que visa o ensino de conteúdos base do Ensino Fundamental na disciplina de Língua Portuguesa para alunos ingressantes no Ensino Médio, considerando que possíveis lacunas deixadas pelo ensino anterior - especialmente o público podem ter influência negativa durante o processo de formação do indivíduo. Nesse sentido, espera-se que o Portal seja uma ferramenta de apoio para o estudante, bem como um recurso pedagógico a ser utilizado pelo professor.

\section{Introdução}

Segundo a escala do Ministério da Educação (MEC), com base no Índice de Desenvolvimento da Educação Básica (Ideb) de 2015, os estudantes de ensino médio estão no nível 2 de 8 em Língua Portuguesa. Considerando esses dados, pode-se constatar que a Educação brasileira passa por graves problemas [Tokarnia 2016].

Através de um formulário on-line, desenvolvido pelos autores, respondido por 70 pessoas (83,6\% cursando o Ensino Médio), constatou-se que apenas 26,1\% lembra dos conteúdos vistos no Ensino Fundamental, problematizando a ideia de que a falha começa no Ensino Médio. Quando o Ensino Fundamental é ineficiente, o estudante acumula lacunas no seu aprendizado, que prejudicam sua formação posterior [Neri et al. 2009].

Diante dos obstáculos observados no cenário da educação, a tecnologia passou a ser vista como uma estratégia a ser utilizada devido ao seu potencial como ferramenta educativa. [Caron 2017]. Nesse sentido, pensando em alternativas que visem atenuar os prejuízos resultantes desse processo educacional, o presente artigo propõe o 
desenvolvimento do Portal: um aplicativo móvel voltado aos conteúdos base de Língua Portuguesa no Ensino Fundamental para alunos ingressantes no Ensino Médio.

\section{Trabalhos relacionados}

Dentre os aplicativos educativos, existem poucos voltados para o ensino da Língua Portuguesa, sendo que, aqueles que estão disponíveis se limitam a tratar sobre as alterações sofridas pelo acordo ortográfico [Gaspar, Oliveira e Oliveira 2015]. Exemplos disso são o "JOE: Jogo Ortográfico Educacional" [Paschoal et al. 2014] e o “OrtograFixe" [Marques e Silva 2012].

Enquanto o primeiro é feito para a plataforma Android, explorando além do acordo ortográfico, acentuação e hífen, o segundo possui um acervo de possibilidades ainda menor, sendo projetado para tablets (Android). Diferentemente dos aplicativos mencionados, o Portal aborda uma temática ainda mais ampla, maior ludicidade e, conteúdo robusto e próprio, como apresentado no tópico 4.

\section{Tecnologia educacional: vínculo ensino-aprendizagem}

Apresentar ao aluno e professor meios eficientes da utilização das ferramentas tecnológicas possibilita a promoção de uma maior construção de conhecimentos. Assim, o Projeto Político Pedagógico das escolas deve conter propostas de trabalho a fim de permitir e comtemplar seu uso, utilizando diferentes mídias como processo de dinamização dos ambientes de aprendizagem e construção de novos saberes.

Segundo Ramos (2012), essa consideração enfatiza a necessidade de análise das tecnologias em sala de aula, não apenas as disponibilizadas pela instituição em que o aluno se encontra, mas também as utilizadas durante as aulas, como os celulares. É possível, então, perceber que a educação necessita dessa metodologia ativa. A tecnologia educacional tem o poder de agregar à educação novos métodos de ensino, e esses, por sua vez, têm o poder de diminuir a evasão escolar, tornando o ensino cada mais interativo.

\subsection{Gamificação: engajamento e motivação na educação}

Gamificação ou Gamification (do inglês) foi um termo criado por Nick Pelling para designar estratégias que visam utilizar recursos, elementos e dinâmicas de jogos em um contexto que não seja de jogo [Domínguez et al. 2013]. O uso dessas estratégias ganhou popularidade por ter a capacidade de motivar os usuários na resolução de problemas, melhorando a assimilação de informações, e contribuindo para o aprendizado.

Basicamente, a gamificação como estratégia em prol da educação se baseia, segundo Borges et al. (2013), nos seguintes objetivos: (i) aprimorar determinadas habilidades; (ii) propor desafios que dão propósito/contexto a aprendizagem; (iii) engajar os alunos em atividades mais participativas, interativas e interessantes; (iv) maximizar o aprendizado de um determinado conteúdo; (v) promover a mudança de comportamento premiando ações adequadas e penalizando as inadequadas; (vi) oferecer mecanismos de socialização e aprendizagem em grupo; e, finalmente, (vii) discutir os benefícios da gamificação na motivação dos alunos para propor soluções aos diversos problemas de aprendizagem. 


\section{Portal: construção e funcionamento}

O aplicativo está sendo desenvolvido com a linguagem Javascript e o framework React Native para a plataforma Android. O conteúdo é desenvolvido junto a um professor de Língua Portuguesa e abarca um compilado de materiais explicativos, seções extras e atividades (voltadas para a Morfologia, conteúdo escolhido com base no formulário).

As seções extras do aplicativo, que abrangem outros tópicos recorrentes na disciplina, são: 1) "Me explica aí!": voltada para o esclarecimento das dúvidas frequentes no dia a dia, como o uso da crase; 2) "Fique ligado!": trata sobre mudanças no acordo ortográfico. 3) Quizzes: liberados com a conclusão do estudo de cada classe gramatical do próprio aplicativo, na tentativa de ratificar o aprendizado.

A Figura 1 demonstra a sequência de telas até o conteúdo principal do aplicativo: após a autenticação do usuário (1.1), o redirecionamento é feito para a tela principal (1.2), que apresenta as classes gramaticais; ao clicar no botão SAIBA MAIS (1.2), um modal surge, com as opções APRENDER e PRATICAR (1.3); a primeira referindo-se ao conteúdo explicativo sobre a classe gramatical selecionada (1.4) e a segunda levando o usuário para as atividades (1.5).
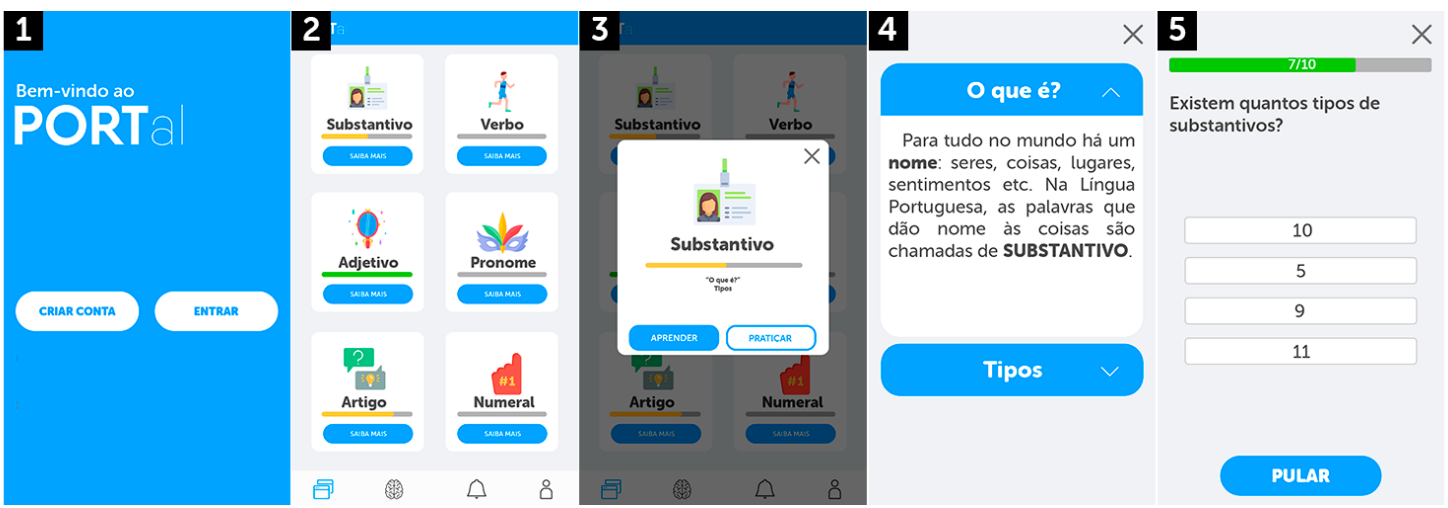

Figura 1. Sequência de telas para o conteúdo principal.

\subsection{Características e idealização}

A utilização de ícones próprios para cada uma das classes, assim como a utilização de imagens e a paleta de cores do aplicativo, como mostra a Figura 1, corroboram para a proposta de transformar a experiência de estudo do usuário, tornando-a mais prazerosa. Além do aspecto visual, dentro do contexto da gamificação, o Portal propõe sua construção voltada aos objetivos propostos (tópico 3.1).

Estão sendo considerados ainda aspectos apontados no formulário supracitado. São eles: quantidade de possibilidades e ferramentas (30,4\%), interação com o usuário $(26,1 \%)$, linguagem objetiva $(15,9 \%)$ e layout e design $(14,5 \%)$. Por fim, ao serem questionados sobre o desejo de ter um aplicativo voltado a conteúdos de Língua Portuguesa, 98,6\% responderam afirmativamente.

\section{Trabalhos futuros}

Como trabalho futuro, pretende-se realizar provas, uma anterior e outra posterior ao uso da ferramenta, com alunos ingressantes no IFRN Campus Ceará-Mirim, a fim de verificar a eficácia do Portal. Pretende-se também implantar um banco de dados, para armazenar 
informações que possibilitem analisar o desempenho dos usuários. Planeja-se ainda introduzir mais elementos de Gamificação, como recompensas, níveis etc. Por fim, o aplicativo estará disponível para download gratuito na Play Store.

\section{Considerações finais}

Com a implementação do Portal, espera-se que as dúvidas com relação a conteúdos de Língua Portuguesa no Ensino Fundamental sejam sanadas ou minimizadas, visto que são abordados conteúdos já vistos, mas não totalmente assimilados. Espera-se também que o aplicativo estimule o estudo e o interesse pela disciplina, possibilitando o uso da ferramenta como material de apoio para os alunos e como recurso pedagógico a ser utilizado por professores.

\section{Referências}

Borges, Simone de S. et al. (2013). "Gamificação Aplicada à Educação: Um Mapeamento Sistemático". In: XXIV Simpósio Brasileiro de Informática na Educação. v. 24, p. 234 - 243.

Caron, Aline (2017), "8 motivos para usar tecnologia em benefício da educação", https://www.positivoteceduc.com.br/blog-inovacao-e-tendencias/motivos-para-usara-tecnologia-na-educacao/, Junho.

Domínguez, Adrián et al. (2013), “Gamifying learning experiences: Practical implications and outcomes". In: Computers \& Education, [s.l.], v. 63, n. 1, p.380-392, abr. 2013. Elsevier BV. http://dx.doi.org/10.1016/j.compedu.2012.12.020.

Gaspar, Wagner, Oliveira, Elaine H. T. e Oliveira, Kelson M. T. (2015), “Aprendizagem da Língua Portuguesa com Dispositivos Móveis: Um Mapeamento Sistemático da Literatura". In: XXVI Simpósio Brasileiro de Informática na Educação.

Marques, Diego, Silva, Ana (2012), “OrtograFixe - Um jogo para apoiar o ensinoaprendizagem das regras da nova reforma ortográfica". In: Anais dos Workshops do Congresso Brasileiro de Informática na Educação.

Neri, Marcelo et al. (Org.) (2009) "Motivos da evasão escolar", http://www.cps.fgv.br/cps/tpemotivos/, Maio.

Paschoal, Luan et al. (2014), “JOE: Jogo Ortográfico Educacional”. In: XXV Simpósio Brasileiro de Informática na Educação.

Ramos, Márcio Roberto Vieira (2012). "O uso de tecnologias em sala de aula". In: $V$ Seminário de Estágio do Curso de Ciências Sociais do Departamento de Ciências Sociais - UEL. Londrina. 11/2012.

Tokarnia, Mariana (2016), "Desempenho de estudantes do ensino médio é menor que o de 20 anos atrás", http://agenciabrasil.ebc.com.br/educacao/noticia/201609/desempenho-de-estudantes-do-ensino-medio-e-menor-que-o-de-20-anos-atras, Junho. 